\title{
Sistem Informasi Pengolahan Data Penduduk Nagari Tanjung Lolo, Kecamatan Tanjung Gadang, Kabupaten Sijunjung Berbasis Web
}

\author{
Arman \\ Dosen STMIK Indonesia Padang \\ Email: arman16309@gmail.com
}

\begin{abstract}
ABSTRAK
Sistem informasi pengolahan data penduduk berbasis web ini diharapkan dapat membantu pembuatan surat keterangan kelahiran, kematian, dan pindah, pencarian data penduduk, mengurangi terjadinya kerusakan dan kehilangan data penduduk karena media penyimpanan yang berupa dokumen, tidak terjadinya duplikasi data penduduk, dan dapat mempersingkat waktu dalam operasional. Dengan adanya media penyimpanan berupa database yang baik diharapkan dapat meningkatkan kinerja seksi pemerintahan dalam melayani dan menyajikan informasi kependudukan kepada masyarakat agar lebih baik, cepat dan aplikasi yang digunakan dapat memberikan kemudahan kepada pengguna dan dapat mempermudah masyarakat dalam mendapatkan informasi dan mendapatkan surat yang cepat dan efisien.
\end{abstract}

Kata kunci : Sistem, informasi, penduduk, Berbasis Web

\section{PENDAHULUAN}

Perkembangan teknologi informasi dizaman sekarang ini semakin pesat. Kebutuhan informasi yang semakin cepat, tepat dan akurat sangat dibutuhkan sekali oleh masyarakat. Tidak dapat hindari lagi bahwa penggunaan komputer hampir sudah merambat disemua bidang, salah satunya bidang Pemerintahan Nagari sudah merupakan salah baik Instansi Pemerintah ataupun Swasta, satu kebutuhan sebagai alat penunjang untuk mempermudah pekerjaan.

Pemerintahan Nagari merupakan suatu intansi pemerintahan terdekat dengan masyarakat. Tuntutan perubahan terus berlangsung seiring dengan berkembangannya ilmu pengetahuan dan teknologi yang semakin canggih. Munculnya berbagai produk teknologi yang dapat dimanfaatkan dalam memberikan peluang kepada seluruh praktisi perangkat intansi pemerintahan untuk meningkatkan kualitas pelayanan terhadap masyarakat.

Berlatar belakang dari permasalahan di Nagari Tanjung Lolo, Kecamatan Tanjung Gadang, Kabupaten Sijunjung, dalam memberikan pelayanan terhadap masyarakat. Dimana Proses pengerjaan pengolahan data kependudukan masih diolah secara manual, belum menggunakan program aplikasi, sehingga proses pengambilan keputusan laporan kependudukan tidak akurat dan memerlukan waktu yang lama, dengan system aplikasi ini diharapkan dapat membantu penyelesaian masalah yang dihadapi 


\section{STUDI PUSTAKA}

\subsection{Pengertian Sistem}

Menurut Dr. H. A. Rusdiana, Drs., M.M. \& Moch.Irfan, S.T., M.Kom (2014:28) bahwa sistem berasal dari bahasa Yunani,yaitu systema, yang berarti himpunan bagian atau komponen yang saling berhubungan secara teratur dan merupakan suatu keseluruhan. Selain itu, bisa diartikan sekelompok elemen yang independen, namun saling berkaitan sebagai satu kesatuan.

Definisi sistem pada dasarnya adalah sekelompok unsur yang erat hubungannya satu dengan yang lain yang berfungsi bersama-sama untuk mencapai tujuan tertentu.

Dari definisi ini dapat dirinci lebih lanjut pengertian sistem secara umum didalam buku Tata Subari (2012:6) yang berjudul "Analisis Sistem Informasi"yaitu sebagai berikut:

1. Setiap sistem terdiri dari berbagai unsur .Unsur - unsur suatu sistem terdiri dari subsistem yang lebih kecil, yang terdiri pula dari kelompok-kelompok unsur yang membentuk subsistem tersebut.

2. Unsur - unsur tersebut merupakan bagian yang tak terpisahkan dari sistem yang bersangkutan. Unsur - unsur sistem berhubungan erat satu sama lain dimana sifat serta kerja sama antar unsur dalam sistem tersebut mempunyai bentuk tertentu.

3. Unsur-unsur didalam sistem bekerja sama untuk mencapai tujuan sistem.

4. Suatu sistem merupakan bagian dari sistem lain yang lebih besar. Sistem pernafasan kita merupakan bagian dari sistem metabolisme tubuh.

\subsection{Pengertian Informasi}

Tujuan dari sistem informasi adalah menghasilkan informasi. Menurut Prof. Dr.
Jogiyanto HM. MBA., Akt. (2009:36), "Informasi (information) adalah data yang diolah menjadi bentuk yang berguna bagi para pemakainya".

Informasi dan data memiliki keterkaitan erat. didalam buku yang berjudul "Basis Data" oleh Edhy Sutanto (2011:13), "Data didefinisikan sebagai bahan keterangan tentang kejadian-kejadian nyata atau fakta yang dirumuskan dalam sekelompok lambang tertentu yang tidak acak, yang menunjukkan jumlah, tindakan atau hal".

Informasi merupakan hasil pengolahan data sehingga menjadi bentuk yang penting bagi penerimanya dan mempunyai kegunaan sebagai dasar dalam pengambilan keputusan yang dapat dirasakan akibatnya secara langsung saat itu juga atau secara tidak langsung pada saat mendatang.

Transformasi data menjadi informasi dapat digambarkan sebagai berikut.

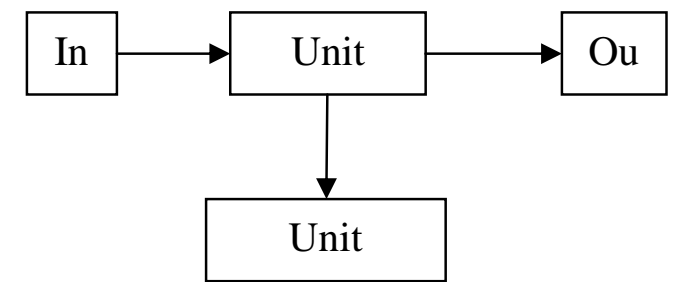

\section{Gambar 2.1 Transformasi data menjadi informasi}

\subsection{Pengertian Sistem Informasi}

Dalam memahami sistem informasi, harus dilihat keterkaitan antara data dan informasi sebagai pembentuk sistem informasi.

Menurut Tata Sutabri didalam buku yang berjudul "Konsep Sistem Informasi" yang ditulis oleh Tata Sutabri(2012:46) mendefinisikan, "Sistem Informasi sebagai suatu sistem di dalam suatu organisasi yang mempertemukan kebutuhan pengolahan transaksi harian yang mendukung fungsi 
operasi organisasi yang bersifat manajerial dengan kegiatan strategi dari suatu organisasi untuk dapat menyediakan kepada pihak luar tertentu dengan laporan-laporan yang diperlukan oleh pihak luar tertentu".

\subsection{Komponen Sistem Informasi}

Didalam buku "Konsep Sistem Informasi" oleh Tata Sutabri. (2012:39), menyebutkan tentang komponen sistem informasi yaitu:

1. Blok Masukan(Input Block)

Input mewakili data yang masuk kedalam sistem informasi.Input yang dimaksud adalah metode dan media untuk menangkap data yang akan dimasukan, yang dapat berupa dokumen-dokumen dasar.

2. Blok model(model block)

Blok ini terdiri dari kombinasi prosedur, logika, dan model matematik yang akan memanipulasi data input dan data yang tersimpan dibasis data dengan cara yang sudah tertentu untuk menghasilkan keluaran yang diinginkan.

3. Blok Keluaran (output block)

Keluaran merupakan informasi yang berkualitas dan dokumentasi yang berguna untuk semua tingkatan manajemen serta semua pemakai sistem.

4. Blok Teknologi(technologi block)

Teknologi merupakan "tool box" dalam sistem informasi. digunakan untuk menerima input, menjalankan model, menyimpan dan mengakses data, menghasilkan dan mengirimkan keluaran, dan membantu pengendalian dari sistem secara keseluruhan.

5. Blok Basis Data (database block)

Merupakan kumpulan data yang saling berkaitan dan berhubungan satu sama lain, tersimpan di perangkat keras komputer dan menggunakan perangkat lunak untuk memanipulasinya.

6. Blok Kendali (control block)
Banyak hal yang dapat merusak sistem informasi, seperti kecurangan, kegagalan sistem itu sendiri, ketidak efisienan dan sabotase. Beberapa pengendalian perlu dirancang dan diterapkan untuk meyakinkan bahwa hal - hal yang dapat merusak sistem dapat dicegah ataupun bila terlanjur terjadi kesalahan - kesalahan dapat langsung cepat diatasi.

\subsection{Pengertian Pengolahan Data}

Menurut Jogiyanto Hartono (2006:9) pengolahan (processing) adalah proses data yang diolah melalui suatu model menjadi informasi, penerima kemudian menerima informasi tersebut, membuat suatu keputusan dan melakukan tindakan, yang berarti menghasilkan suatu tindakan yang lain yang akan membuat sejumlah data kembali. Data tersebut akan ditangkap sebagai input, diproses kembali lewat suatu model dan seterusnya membentuk suatu siklus. Siklus ini disebut juga dengan siklus pengolahan data (data processing cycles).

\subsection{Pengertian Penduduk}

Penduduk adalah semua orang yang berdomisili di wilayah geografis Indonesia selama enam bulan atau lebih dan atau mereka yang berdomisili kurang dari enam bulan tetapi bertujuan menetap. Pertumbuhan penduduk diakibatkan oleh tiga komponen yaitu: fertilitas, mortalitas dan migrasi. http://id.scribd.com/doc/91037202/Pengertia n-Penduduk/IndahPusparini diakses tanggal 1 Desember 2014.

\subsection{Fertilitas (Kelahiran)}

Dalam Fertilitas sebagai istilah demografi diartikan sebagai hasil reproduksi yang nyata dari seorang wanita atau sekelompok wanita. Dengan kata lain fertilitas ini menyangkut banyaknya bayi yang lahir 
hidup. Natalitas mempunyai arti yang sama dengan fertilitas hanya berbeda ruang lingkupnya. Fertilitas menyangkut peranan kelahiran pada perubahan penduduk sedangkan natalitas mencakup peranan kelahiran pada perubahan penduduk dan reproduksi manusia.

\subsection{Mortalitas (Kematian)}

Mortalitas atau kematian merupakan salah satu di antara tiga komponen demografi yang dapat mempengaruhi perubahan penduduk. Informasi tentang kematian penting, tidak saja bagi pemerintah melainkan juga bagi pihak swasta, yang terutama berkecimpung dalam bidang ekonomi dan kesehatan. Mati adalah keadaan menghilangnya semua tanda - tanda kehidupan secara permanen, yang bisa terjadi setiap saat setelah kelahiran hidup.

\section{ANALISA DAN HASIL}

\subsection{Analisa Sistem Yang Sedang Berjalan}

Berdasarkan hasil analisa terhadap sistem yang sedang berjalan, maka penulis melakukan perancangan sistem baru dengan menggunakan bahasa pemograman php dan mysql sebagai database servernya. Dengan pemrograman ini diharapkan dapat:

1. Mempermudah pembuatan laporan.

2. Mempermudah pekerjaan bagian administrasi dan operator untuk mengolah data.

Informasi dapat diketahui setiap saat dan penyimpanan datanya tidak memerlukan banyak tempat, maka rancangan sistem yang diusulkan dapat dilihat pada Aliran sistem Informasi dibawah ini :

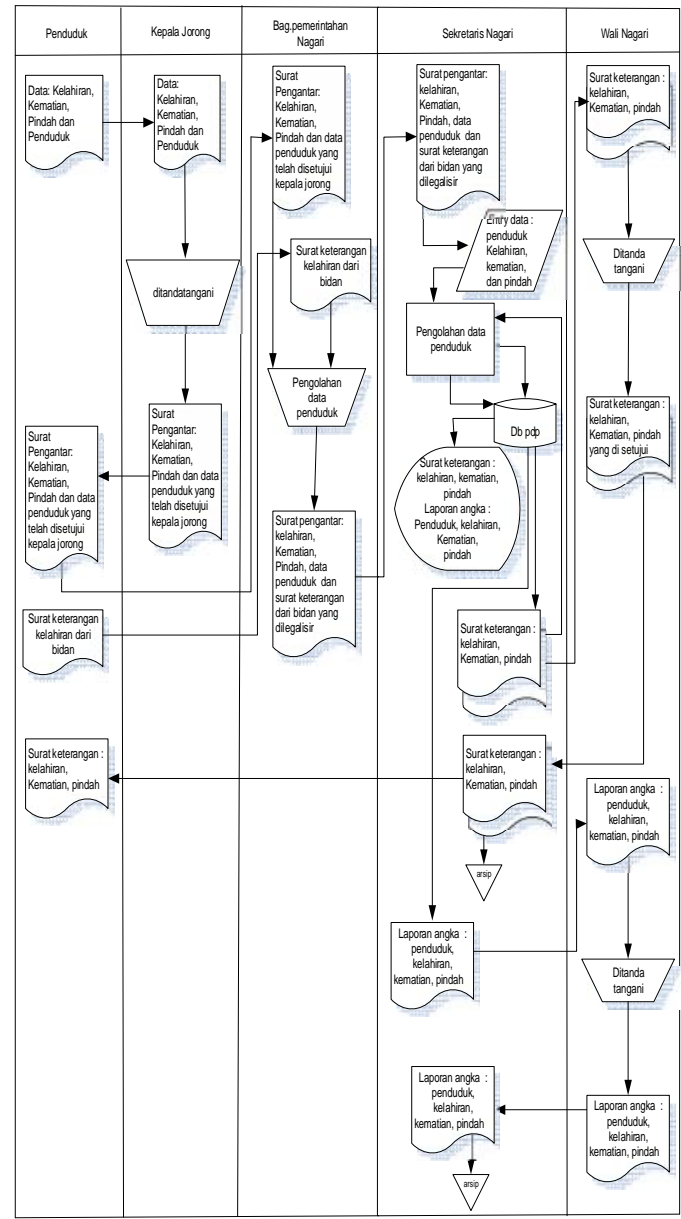

Gambar 3.1 : Aliran Sistem Informasi Yang diusulkan

\subsection{Output}

1. Surat Keterangan Kelahiran

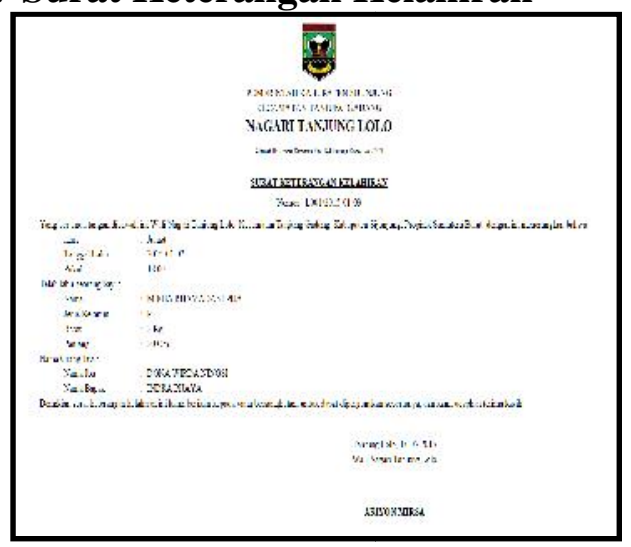

Gambar 3.2 Surat Keterangan Kelahiran 
Penelitian Bidang Komputer Sains dan Pendidikan Informatika V2.i2(163-170)

\section{Surat keterangan Kematian}

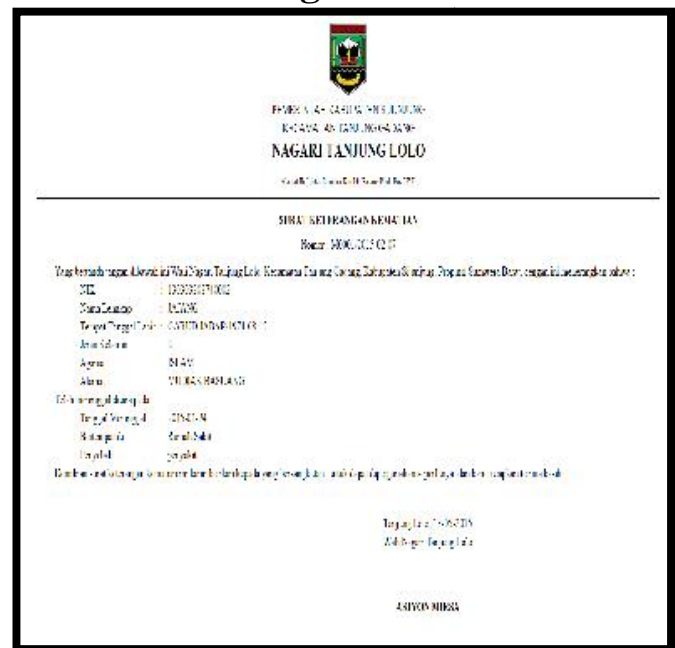

Gambar 3.3 Surat Keterangan Kematian.

\section{Surat Keterangan pindah}

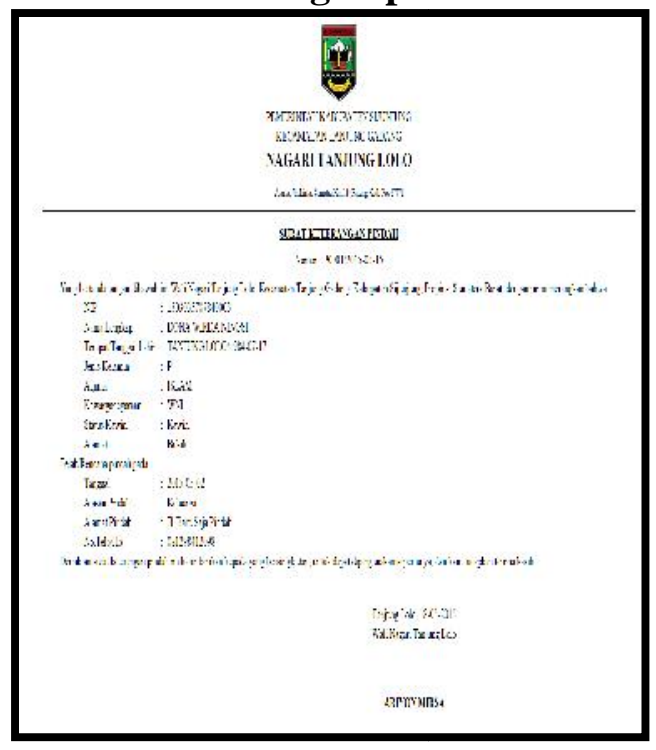

Gambar 3.4 Surat Keterangan Pindah.
4. Laporan Data penduduk

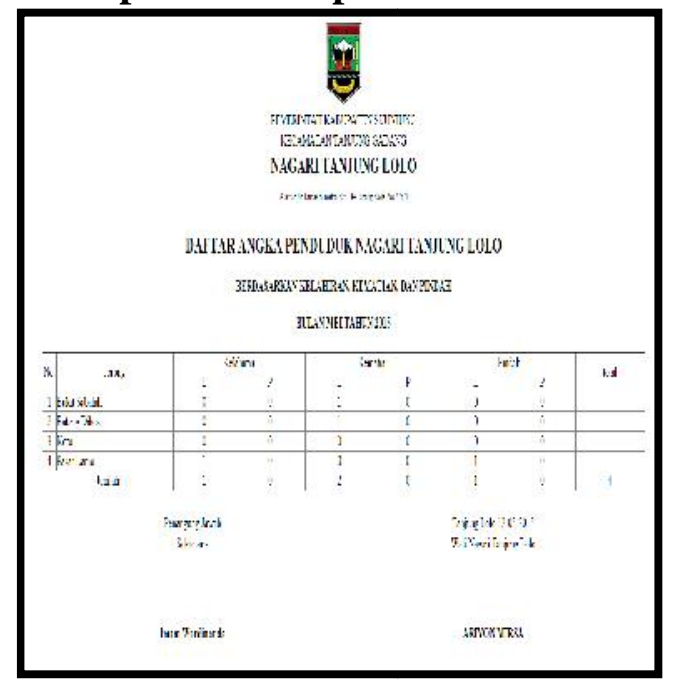

Gambar 3.5 Laporan Data Penduduk.

5. Laporan Data Kelahiran

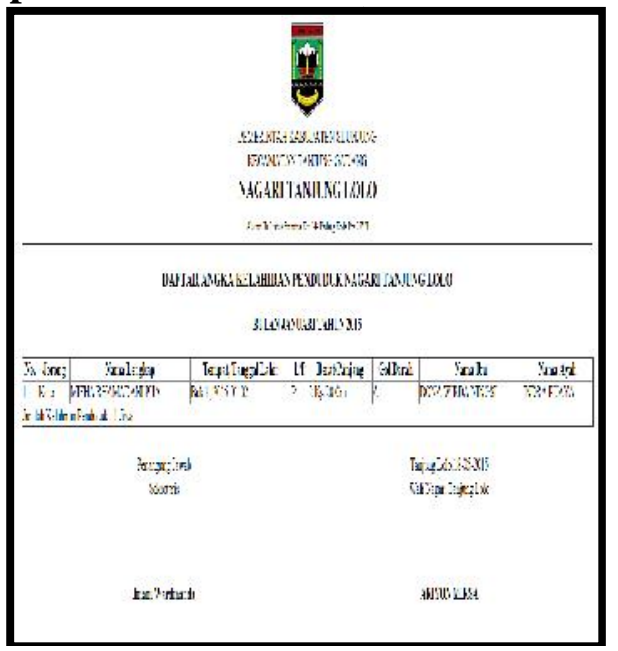

Gambar 3.6 Laporan Data Kelahiran 
Penelitian Bidang Komputer Sains dan Pendidikan Informatika V2.i2(163-170)

\section{Laporan Data Kematian}

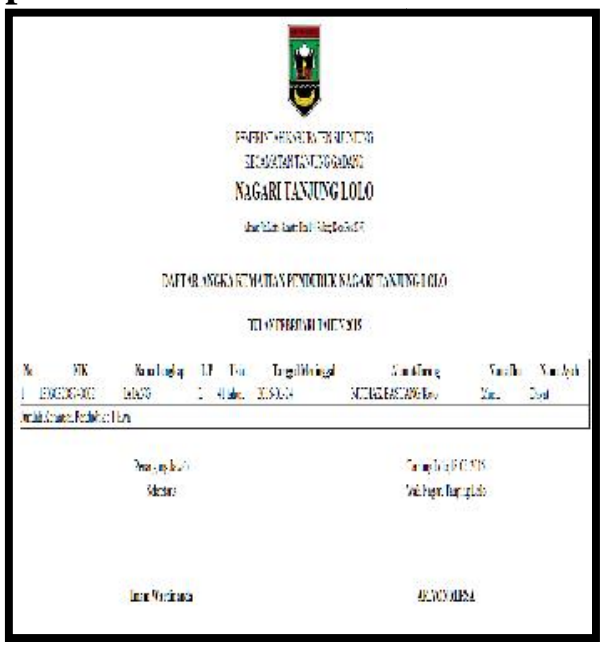

Gambar 3.7 Laporan Data Kematian.

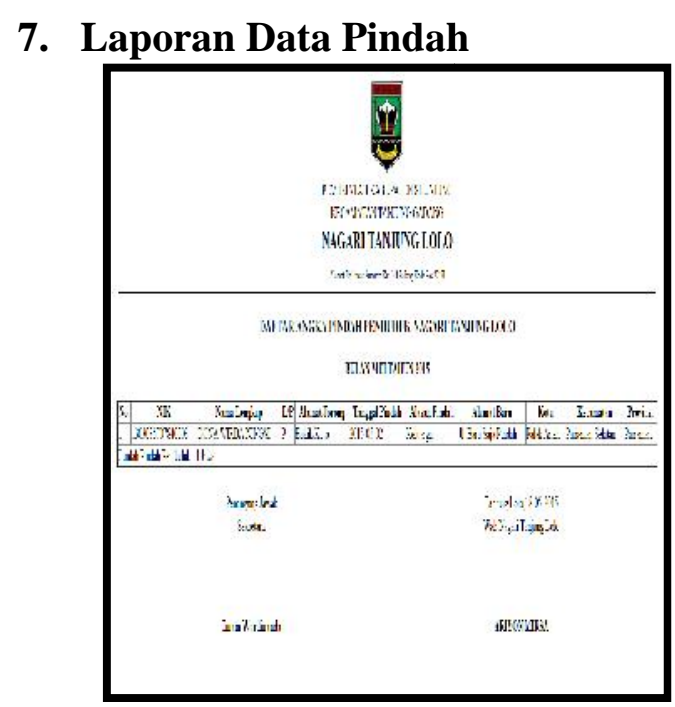

Gambar 3.8 Laporan Data Pindah.

\subsection{Input}

1. Input Data Penduduk

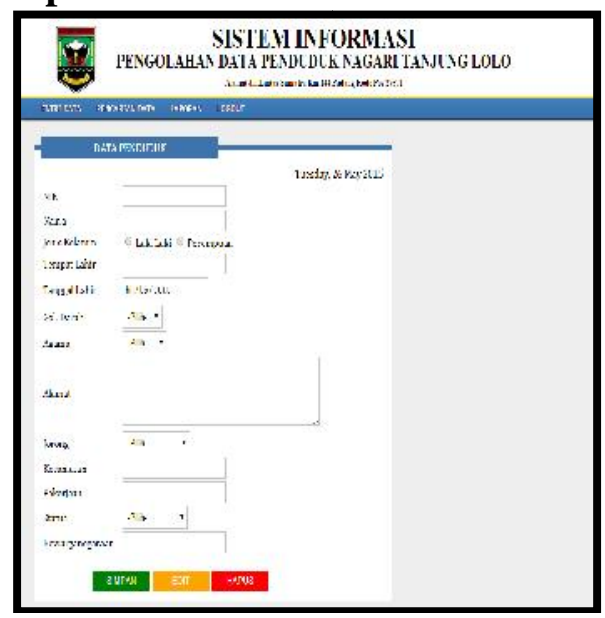

Gambar 3.9 Form Entri Data Penduduk.

\section{Input Data Kelahiran}

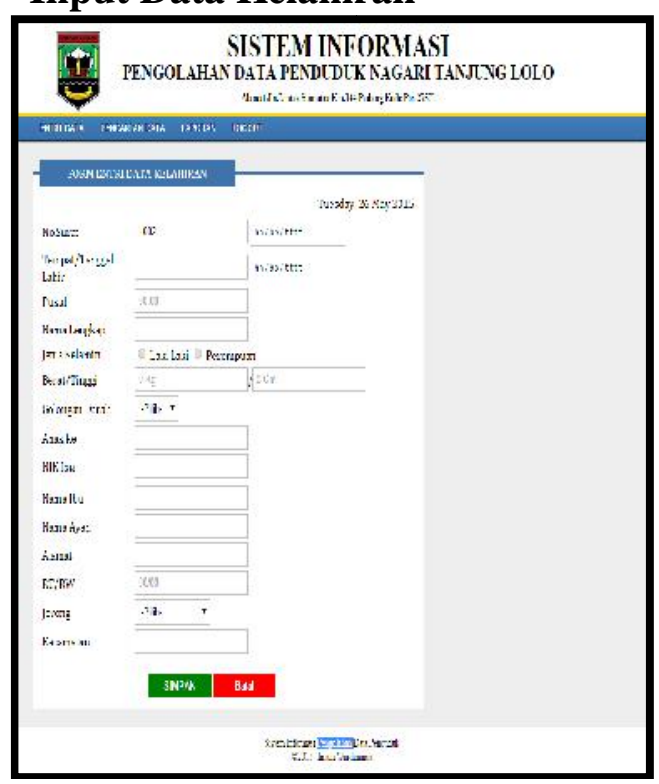

Gambar 3.10 Form Input Data

Kelahiran. 
Penelitian Bidang Komputer Sains dan Pendidikan Informatika V2.i2(163-170)

\section{Input Data Kematian}

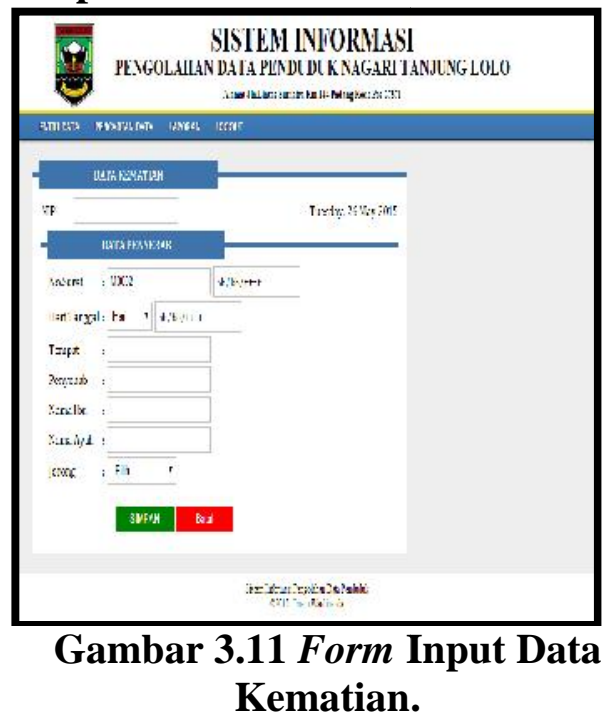

\section{Input Data Pindah}

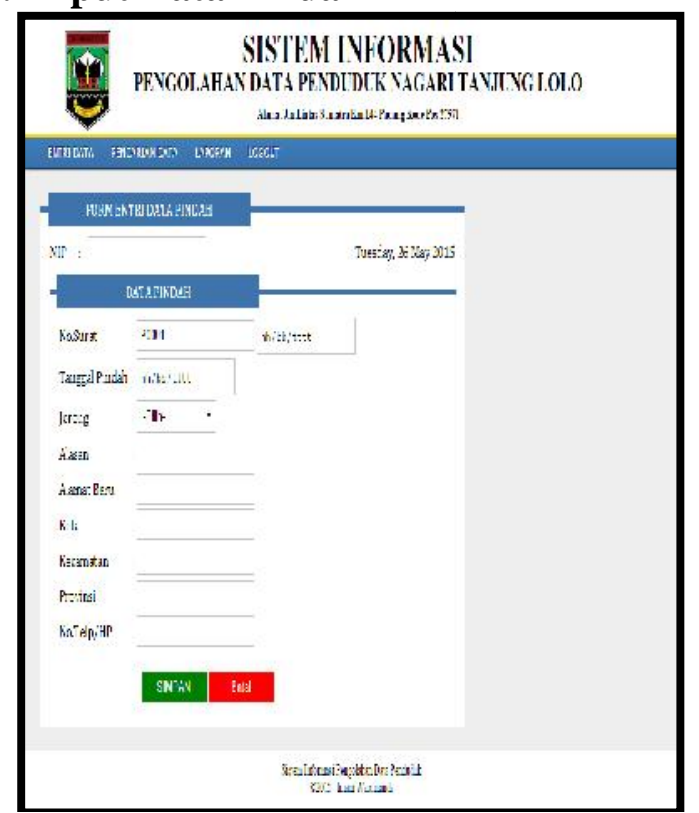

Gambar 3.12 Form Entri Data Pindah.
5. Input Data Pegawai

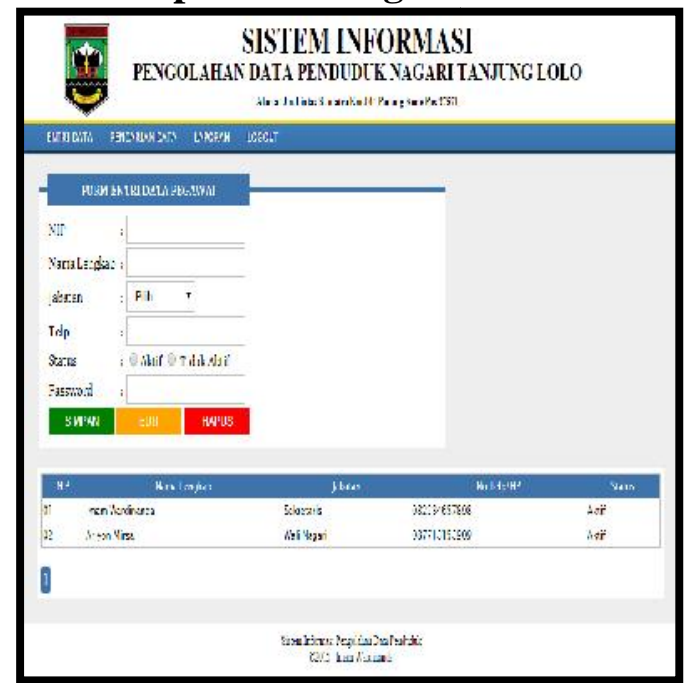

Gambar 3.13 Form Input Data Pegawai.

\section{Input Data Login}

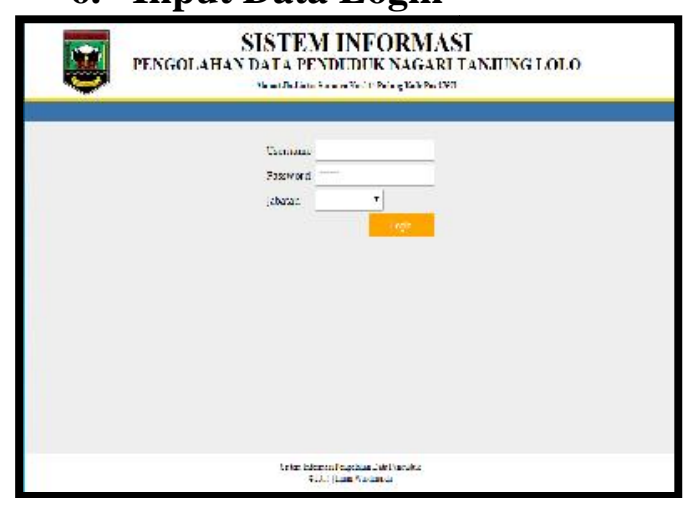

Gambar 3.14 Form Login 


\section{Menu Utama

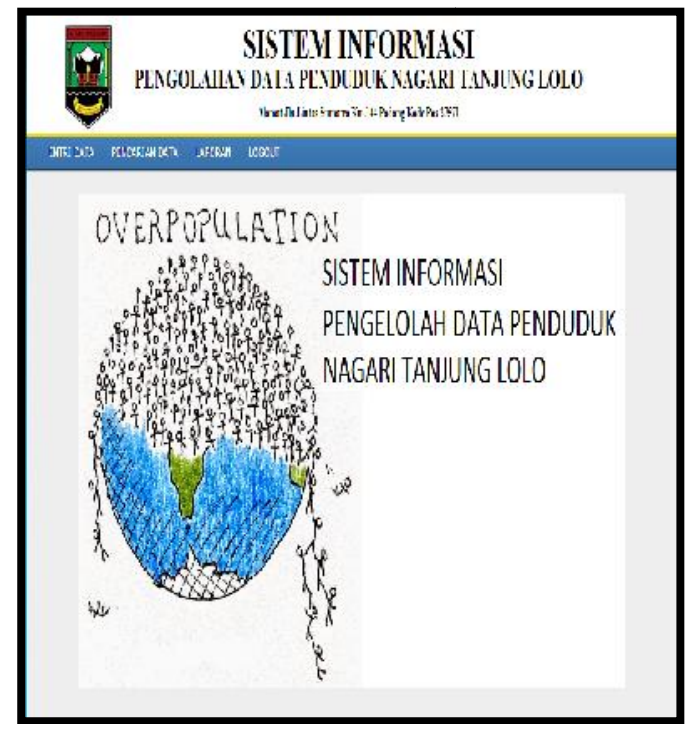 \\ Gambar 3.15 Menu Utama Sistem Informasi Pengolahan Data Penduduk Nagari Tanjung Lolo}

\section{KESIMPULAN}

Sistem Informasi pengolahan data penduduk Berbasis Web ini diharapkan dapat menjadi bahan atau salah satu referensi bagi penerintahan Nagari untuk meningkatkan pelayanan pada masyarakat dan warga didalam pelayanan ke pada masyarakat. Ada beberapa kesimpulan dan saran yang dapat disampaikan sebagai hasil dari evaluasi perancangan sistem dalam penelitian ini.

1. Dengan proses pengolahan yang dilakukan secara komputerisasi seperti pemasukan dan pembaharuan serta pencarian data penduduk membuat Surat Keterangan Kelahiran, Kematian, dan Pindah dapat meminimalisasikan kesalahan pada proses penambahan data serta mempermudah proses pencarian data penduduk.

2. Dengan adanya penyimpanan data yang sudah dengan database, maka kemungkinan tidak akan lagi terjadi duplikasi data.
3. Dengan sistem informasi pengolahan data penduduk ini, diharapkan dapat menjadi sebuah sistem pelayanan kependudukan yang dapat meningkatkan pelayanan terhadap masyarakat.

\section{SARAN}

Adapun beberapa saran yang diusulkan yaitu:

1. Saat ini Jaringan komputer diperluas lagi menjadi Metropolitan Area Network (MAN).

2. Untuk kedepannya aplikasi dilakukan secara online atau berbasis web, agar penduduk dan desa bisa melakukan entri data sendiri.

3. Penggunaan program aplikasi tidak hanya dapat dilakukan oleh bagian pelayanan.

4. Diadakan pelatihan sebelum menggunakan aplikasi ini.

\section{DAFTAR PUSTAKA}

Abdul Kadir (2014). Pengenalan Sistem Informasi. Yogyakarta : Andi Offiset.

Dr. Ir. Eko Nugroho, M.si (2008). Sistem

Informasi Manajemen. Yogyakarta: Andi Offiset.

Jogiyanto Hartono (2006). Analisis dan Desain Sistem Informasi. Yogyakarta : Andi Offiset

Amsal Djunid dan Rita Afyeni: (2007). Sistem Informasi Manajemen. Padang : STMIK Indonesia Padang

Menurut M.Syafii (2005). Panduan Membuat Aplikasi Database dengan PHP 5 MySQL PostgreSQL Oracle. Yogyakarta : Andi

Menurut Prof. Jogiyanto HM, MBA, Akt. (2009). Sistem Teknologi Infomasi. Yogyakarta : Andi Offiset 